\title{
Pulmonary vascular permeability index and global end-diastolic volume: are the data consistent in patients with femoral venous access for transpulmonary thermodilution: a prospective observational study
}

Helena Berbara, Sebastian Mair, Analena Beitz, Benedikt Henschel, Roland M Schmid and Wolfgang Huber ${ }^{*}$

\begin{abstract}
Background: Transpulmonary thermodilution (TPTD) derived parameters are used to direct fluid management in ICU-patients. Extravascular lung water EVLW and its ratio to pulmonary blood volume (pulmonary vascular permeability index PVPI) have been associated with mortality. In single indicator TPTD pulmonary blood volume (PBV) is estimated to be $25 \%$ of global end-diastolic volume (GEDV). A recent study demonstrated marked overestimation of GEDV indexed to body-surface area (BSA; GEDVI) when using a femoral central venous catheter (CVC) for indicator injection due to the additional volume measured in the vena cava inferior. Therefore, a correction formula derived from femoral TPTD and biometric data has been suggested. Consequence, one of the commercially available TPTD-devices (PiCCO; Pulsion Medical Systems, Germany) requires information about CVC site. Correction of GEDVI for femoral CVC can be assumed. However, there is no data if correction also pertains to unindexed GEDV, which is used for calculation of PBV and PVPI. Therefore, we investigated, if also GEDV, PBV and PVPI are corrected by the new PiCCO-algorithm.
\end{abstract}

Methods: In this prospective study 110 triplicate TPTDs were performed within 30 hours in 11 adult ICU-patients with PiCCO-monitoring and femoral CVC. We analyzed if the femoral TPTD correction formula for GEDVI was also applied to correct GEDV. Furthermore, we compared PVPI $\left.\right|_{\text {displayed }}$ to PVPI calculated which was calculated as $\mathrm{EVLW}$ displayed $/\left(0.25^{*} \mathrm{GEDV} V_{\text {displayed }}\right)$.

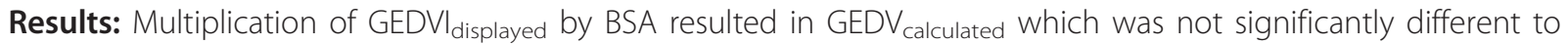
$\mathrm{GEDV}_{\text {displayed }}(1459 \pm 365 \mathrm{~mL}$ vs. $1459 \pm 366 \mathrm{~mL})$ suggesting that correction for femoral indicator injection also pertains to GEDV displayed. However, PVPI displayed was significantly lower than PVPI calculated $(1.64 \pm 0.57$ vs. $2.27 \pm 0.72 ; \mathrm{p}<0.001)$. In addition to a bias of $-0.64 \pm 0.22$ there was a percentage error of $22 \%$. Application of the correction formula suggested for GEDVI to PVPI displayed reduced the bias of PVPI $\left.\right|_{\text {displayed }}$ Compared to EVLW/PBV from $-0.64 \pm 0.22$ to $-0.10 \pm 0.05$ and the percentage error from $22 \%$ to $4 \%$.

Conclusions: Correction for femoral CVC in the PiCCO-device pertains to both GEDVI displayed and GEDV displayed, but not to PVPI displayed. To provide consistent information, PVPI should be calculated based on GEDV corrected in case of femoral CVC.

Keywords: Lung edema, ARDS, Extravascular lung water, Pulmonary vascular permeability index, Transpulmonary thermodilution, Femoral venous catheter, Hemodynamic monitoring, Cardiac output, Catheter site, PiCCO

\footnotetext{
* Correspondence: wolfgang.huber@|rz.tum.de

II. Medizinische Klinik und Poliklinik, Klinikum rechts der Isar der Technischen

Universität München, Ismaninger Straße 22, D-81675 München, Germany
} 


\section{Background}

Appropriate fluid supply is a cornerstone of critical care. In addition to cardiac output $\mathrm{CO}$, transpulmonary thermodilution (TPTD) provides extravascular lung water (EVLW) reflecting pulmonary edema and the preload parameter global end-diastolic volume (GEDV) [1-6]. Increased EVLW is associated to mortality [3,7-11]. GEDV and its changes are associated to $\mathrm{CO}$ [6] and algorithms based on GEDV have been shown to improve outcome [12]. Moreover, the relation of EVLW and pulmonary blood volume (PBV) might be useful to differentiate the etiology of pulmonary edema $[13,14]$. PBV can be determined using double-indicator TPTD technique [13]. Single indicator TPTD is much more common in clinical routine and estimates PBV as about 25\% of GEDV [14]. EVLW/PBV-ratio has been termed pulmonary vascular permeability index "PVPI". Several studies demonstrated that higher values of PVPI are associated to pulmonary edema with increased permeability of the alveolo-capillary barrier [14]. Increased PVPI has been found in patients with ARDS resulting from pulmonary (e.g. pneumonia) or secondary (e.g. sepsis) pulmonary impairment. By contrast hydrostatic pulmonary edema due to congestive heart failure usually does not result in marked increases of PVPI since EVLW and PBV are increased to a similar extent $[13,14]$.

Although TPTD has become part of clinical routine, several pitfalls have to be kept in mind. Two recent studies demonstrated marked overestimation of GEDV in case of performing TPTD indicator injection using a femoral venous access due to the additional volume of vena cava inferior (VCI) participating in TPTD [15,16]; Figure 1).

The authors suggested a correction formula for GEDV indexed to predicted body surface area (GEDVI) based on data derived from femoral TPTD and biometric information. As a consequence of these data one the manufacturer of the PiCCO device (Pulsion Medical Systems, Feldkirchen, Germany) implemented a new software requiring the information about CVC site (femoral or jugular/subclavian) and correcting GEDVI in case of femoral injection. Although jugular and subclavian vein access might be the preferred sites for CVC insertion, several recent studies on catheter related bloodstream infections have demonstrated that femoral venous access was used in about 20 to $35 \%$ of all catheter insertions $[17,18]$. Therefore, results of TPTD might be substantially altered in about one third of cases without appropriate correction.

To the best of our knowledge there are no data available if the new PiCCO algorithm also corrects unindexed GEDV and PVPI in case of femoral CVC.

Furthermore, data on PVPI were not investigated in both previous papers on TPTD using a femoral CVC $[15,16]$.

Therefore, it was the aim of our study to investigate if in case of femoral indicator injection

- GEDV in the new PiCCO algorithm is given based on the correction of GEDVI and

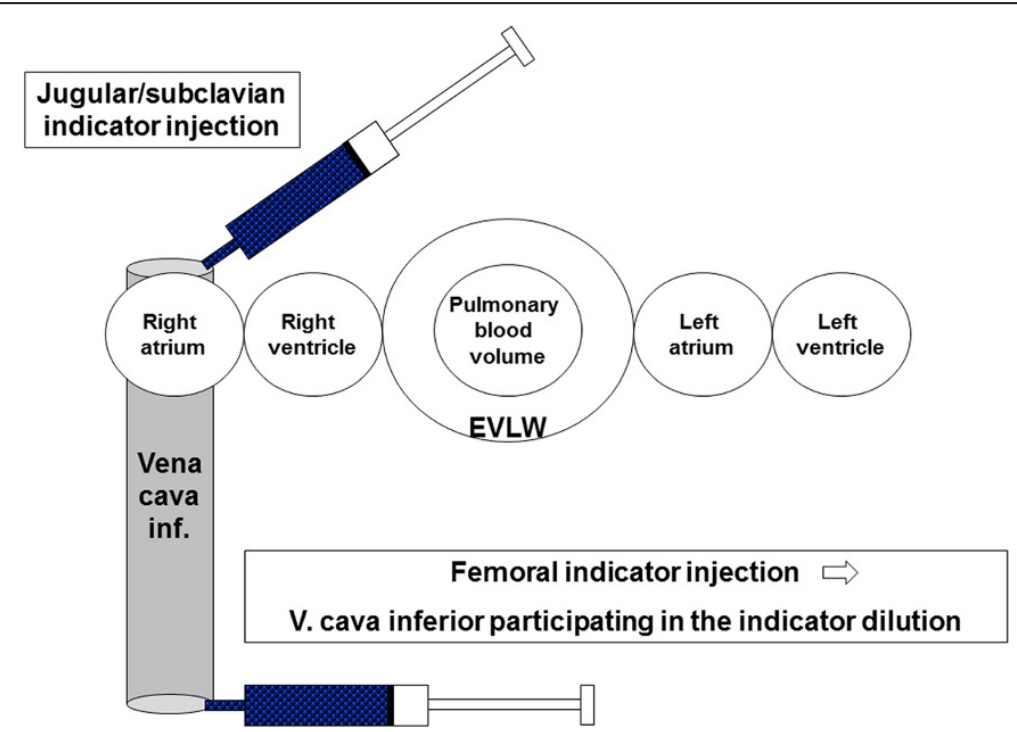

Figure 1 Comparison of transpulmonary indicator dilution (TPTD) using femoral central venous catheter (CVC) instead of jugular or subclavian CVC. Obviously, the distribution volume for the indicator is augmented by the volume of vena cava inferior in case of femoral indicator injection. This results in diminished indicator concentration and overestimation of global enddiastolic volume GEDV. In single indicator dilution technique GEDV is calculated as difference of the total dilution volume (intrathoracic thermovolume ITTV) minus the sum of pulmonary blood volume PBV and extravascular lung water EVLW: GEDV = ITV- (EVLW + PBV). The sum (PBV + EVLW) is thermed pulmonary thermovolume PTV, which is directly derived from the thermodilution curve. Therefore, it can be assumed not to be altered by the additional dilution volume of VCl participating in TPTD. 
- PVPI is based on corrected GEDV and corrected pulmonary blood volume.

\section{Methods}

The study was approved by the institutional review board (Ethikkommission der Fakultät für Medizin der Technischen Universität München, Munich, Germany).

All patients or their legal representatives gave written informed consent.

We prospectively performed 110 TPTDs in 11 patients with femoral indicator injection. All patients were recruited between October 2013 and January 2014.

Ten triplicate TPTDs per patient were performed with $15 \mathrm{~mL}$ cold saline within a total of $30 \mathrm{~h}$. TPTD was performed as described previously using the PiCCO-2 device (Pulsion Medical Systems, Feldkirchen, Germany) $[6,16,19]$ and a 5-lumen CVC (Multicath 5; Vygon; Aachen, Germany). All PiCCO-2 devices were equipped with the V3.1 algorithm requiring information about the venous catheter site which was set to "femoral" CVC in all patients.

Immediately after triplicate TPTD absolute and indexed mean values were documented for GEDV, GEDVI, EVLW, EVLWI and PVPI as displayed by the device. Parameters displayed by the device were subscripted with "displayed" (see Table 1).

The main purpose of the study was to investigate the consistency of displayed values by comparing displayed data (e.g. GEDV $_{\text {displayed }}$ PVPI displayed $_{\text {) }}$ to the corresponding values derived from calculation specified with the subscript "calculated" (GEDV caculated $_{\text {PVPI }}$ calculated $)$.

If displayed and calculated values were inconsistent, we investigated whether the inconsistency could be explained by (non-) application of the recently suggested correction formula for the displayed values parameters [16]. In this case "ex post" correction by our formula

Table 1 Terminology of thermodilution-derived parameters

\begin{tabular}{|c|c|c|}
\hline Subscript & Meaning & $\begin{array}{l}\text { Parameters } \\
\text { analyzed }\end{array}$ \\
\hline \multirow[t]{4}{*}{ "displayed" } & \multirow{4}{*}{$\begin{array}{l}\text { Values as displayed by the PiCCO } \\
\text { monitor }\end{array}$} & GEDVI $I_{\text {displayed }}$ \\
\hline & & GEDV $V_{\text {displayed }}$ \\
\hline & & EVLW displayed \\
\hline & & $\mathrm{PVPI}_{\text {displayed }}$ \\
\hline \multirow[t]{2}{*}{ "calculated" } & $\begin{array}{l}\text { Parameters calculated based on } \\
\text { parameters displayed on the monitor. }\end{array}$ & GEDV $_{\text {calculated }}$ \\
\hline & $\begin{array}{l}\text { These parameters should be consistent } \\
\text { with corresponding displayed values. }\end{array}$ & $\mathrm{PVPI}_{\text {calculated }}$ \\
\hline \multirow[t]{2}{*}{ "corrected" } & \multirow{2}{*}{$\begin{array}{l}\text { Parameters derived from correction of the } \\
\text { displayed values. Corrected parameters } \\
\text { were used for comparison to calculated } \\
\text { values (only used in case of inconsistency } \\
\text { of displayed and calculated values). }\end{array}$} & PVPI ${ }_{\text {corrected }}$ \\
\hline & & GEDV $V_{\text {uncorrected }}$ \\
\hline
\end{tabular}

should result in a consistency of the "corrected" values (with the subscript "corrected") and the calculated values.

To analyze if the femoral TPTD correction formula for $G_{E D V I} I_{\text {displayed }}$ was only applied for GEDVI displayed $_{\text {or }}$ if also GEDV $V_{\text {displayed }}$ is corrected in case of femoral indicator injection, we calculated $G_{E D V}$ calculated using the formula:

$$
\mathrm{GEDV}_{\text {calculated }}=\mathrm{GEDVI}_{\text {displayed }} * \mathrm{BSA}_{\text {predicted }} .
$$

Finally, GEDV $V_{\text {displayed }}$ was compared to $G E D V_{\text {calculated. }}$.

In a second step we analyzed, if PVPI displayed $_{\text {is calculated }}$ based on a GEDV $V_{\text {displayed }}$ corrected for femoral indicator injection. Therefore, we compared PVPI displayed $_{\text {to PVPI- }}$ calculated using the formula PVPI $\mathrm{Calculated}=\mathrm{EVLW}_{\text {displayed }} /$ $\left(0.25 * \mathrm{GEDV}_{\text {displayed }}\right)$.

Predicted bodyweight $\mathrm{BW}$ predicted was calculated using the formula:

$$
\begin{aligned}
& \text { Predicted bodyweight } \mathrm{BW}_{\text {predicted }}[\mathrm{kg}] \text { : } \\
& \text { Male : } 50+0.91 *(\text { height }-152.4) \\
& \text { Female }: 45.5+0.91 *(\text { height }-152.4)
\end{aligned}
$$

Predicted body surface area $\mathrm{BSA}_{\text {predicted }}$ was calculated using $\mathrm{BW}_{\text {predicted }}$ instead of actual bodyweight in the Dubois formula:

$$
\begin{aligned}
\operatorname{BSA}_{\text {Dubois }}\left[\mathrm{m}^{2}\right]= & 0.007184 * \text { weight }[\mathrm{kg}]^{0.425} \\
& * \text { height }[\mathrm{cm}]^{0.725}
\end{aligned}
$$

The correction formula suggested for correction of uncorrected femoral indicator injection derived $G E D V_{\text {uncorrected }}$ is $\mathrm{GEDVI}_{\text {corrected }}\left[\mathrm{mL} / \mathrm{m}^{2}\right]=0.539$ *GEDVI $\mathrm{Gncorrected}_{\text {- }}$ $15.17+24.49 * \mathrm{CI}_{\text {uncorrected }}+2.311^{*} \mathrm{BW}_{\text {ideal }}[16]$.

Ideal bodyweight $\mathrm{BW}_{\text {ideal }}$ was calculated using the formula:

$$
\begin{aligned}
& \text { Ideal bodyweightBW } \mathrm{W}_{\text {ideal }}[\mathrm{kg}]: \\
& \text { Male : }(\text { height }-100) \times 0.9 \\
& \text { Female : (height }-100) \times 0.85
\end{aligned}
$$

Correlation of $\mathrm{GEDV}_{\text {calculated }}$ and $\mathrm{GEDVI}_{\text {displayed }}$ was analyzed using Spearman correlation. Comparisons of GEDV $_{\text {displayed }}$ vs. GEDV calculated $_{\text {PVPI }}$, displayed $_{\text {Vs. PVPI }}$ calculated and PVPI $I_{\text {corrected }}$ Vs. PVPI calculated were performed $_{\text {. }}$ using Wilcoxon-test for paired samples, respectively. Bland-Altman analyses and calculation of percentage error (PE) were used for these comparisons as described previously [20,21]. Bland-Altman analyses were corrected for repeated measurements allowing variability of true values within each subject [22].

All analyses were performed using IBM SPSS Statistics 21 (SPSS inc., Chicago, IL, USA). 
Table 2 Patients characteristics (mean \pm standard deviation; numbers and percentages)

\begin{tabular}{lc}
\hline Gender & $\begin{array}{c}\mathbf{5 / 1 1} \text { (45\%) female; 6/11 (55\%) } \\
\text { male }\end{array}$ \\
\hline Age [years] & $59.9 \pm 11.9$ \\
Height $[\mathrm{cm}]$ & $171.1 \pm 11.7$ \\
APACHE-Il score & $16 \pm 6$ \\
SOFA score & $6.5 \pm 2.5$ \\
Actual bodyweight $[\mathrm{kg}]$ & $72.8 \pm 19.1$ \\
Predicted bodyweight $[\mathrm{kg}]$ & $65.0 \pm 12.0$ \\
Ideal bodyweight $[\mathrm{kg}]$ & $62.5 \pm 11.4$ \\
Predicted body surface area $\left[\mathrm{m}^{2}\right]$ & $1.76 \pm 0.22$ \\
Aetiology & \\
$\quad$ Sepsis & $7 / 11(64 \%)$ \\
$\quad$ ARDS & $1 / 11(9 \%)$ \\
$\quad$ Cirrhosis & $1 / 11(9 \%)$ \\
$\quad$ Cardiogenic shock & $2 / 11(18 \%)$ \\
Measurements under mechanical & $60 / 110(54.5 \%)$ \\
ventilation &
\end{tabular}

\section{Results}

\section{Patients characteristics}

Five female and six male patients were included. Patients characteristics are shown in Table 2.

$\mathrm{GEDV}_{\text {calculated }}$ was obtained by multiplying $\mathrm{GEDVI}_{\text {displayed }}$ by BSA $_{\text {predicted. }}$. As demonstrated in Figure $2 \mathrm{GEDV}_{\text {calculated }}$ and $\mathrm{GEDV}_{\text {displayed }}$ significantly correlated $\left(\mathrm{r}^{2}=1.0 ; \mathrm{p}<\right.$ $0.001)$ and were not significantly different $(1459 \pm 365 \mathrm{~mL}$ vs. $1459 \pm 366 \mathrm{~mL})$.
This confirms that correction for femoral venous catheter site pertains to both GEDVI displayed $_{\text {and }}$ GEDV displayed $_{\text {. }}$ Consequently, calculation of PVPI calculated $_{\text {based }}$ on $E{ }^{2} W_{\text {displayed }}$ and GEDV $V_{\text {displayed }}$ should result in a PVPIcalculated identical with PVPI displayed. $_{\text {. }}$

However, PVPI displayed was significantly lower than PVPIcalculated (Figure 3; $1.64 \pm 0.57$ vs. $2.27 \pm 0.72 ; \mathrm{p}<0.001$ ). In addition to a bias of $-0.64 \pm 0.22$ Bland-Altman analysis demonstrated a percentage error of $22 \%$ and upper and lower limits of agreement of -0.199 and -1.075 (Figure 4).

This could be explained if instead of the corrected $G \mathrm{EVV}_{\text {displayed }}$ an uncorrected $\mathrm{GEDV}_{\text {uncorrected }}$ was used for calculation of PBV and PVPI displayed. $_{\text {. }}$

Based on this hypothesis and also assuming that the formula for femoral indicator injection suggested by our group is used by the latest PiCCO algorithm we determined PVPI ${ }_{\text {corrected }}$ by multiplying PVPI ${ }_{\text {calculated }}$ by the ratio $\mathrm{GEDV}_{\text {uncorrected }} / \mathrm{GEDV}_{\text {displayed. }}$.

As shown in Figure 5 the bias of PVPI ${ }_{\text {displayed.d }}$ to EVLW/ PBV could be reduced from $-0.64 \pm 0.22$ to $-0.10 \pm 0.05$. Furthermore, percentage error decreased from $22 \%$ to $4 \%$ with upper and lower limits of agreement of -0.009 and -0.190 (Figure 5).

\section{Discussion}

Despite improving outcome by a number of specific and unspecific approaches such as low tidal volume [23], extracorporeal lung assist [24] and prone positioning [25] ARDS still carries a high mortality of up to $65 \%$ [23-26]. Well balanced fluid management providing appropriate resuscitation [27] as well as avoiding fluid

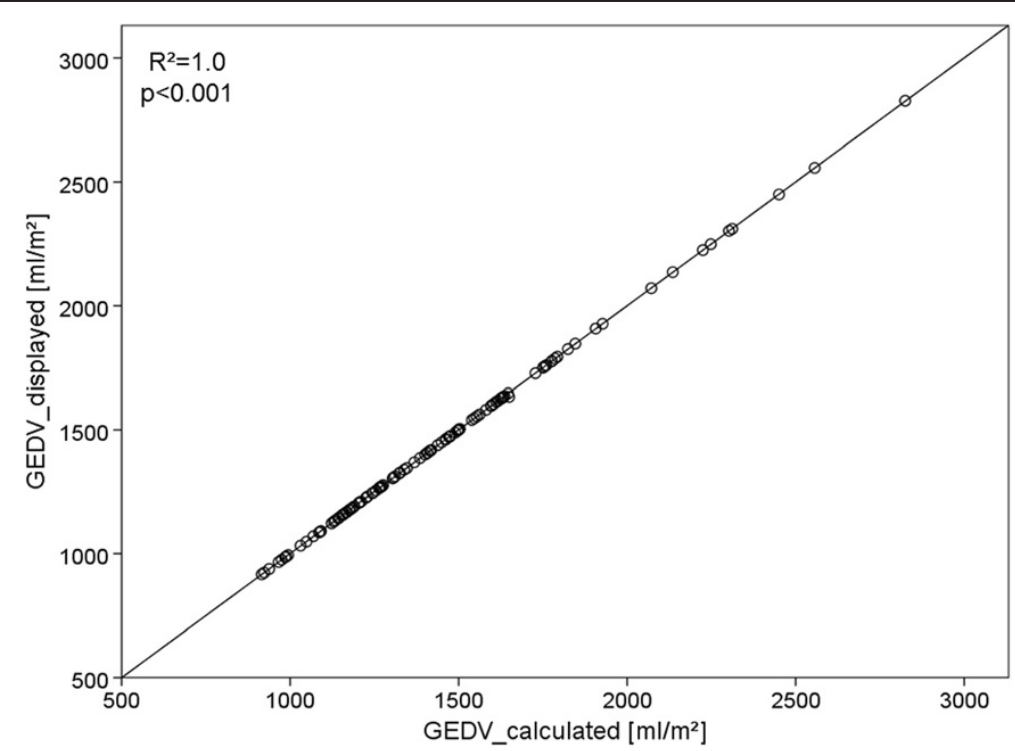

Figure 2 Scatter plot depicting the correlation of GEDV as displayed by the PiCCO-2 device (GEDV displayed $)$ vs. GEDV calculated as product GEDVI displayed $^{*}$ predicted body surface area. 


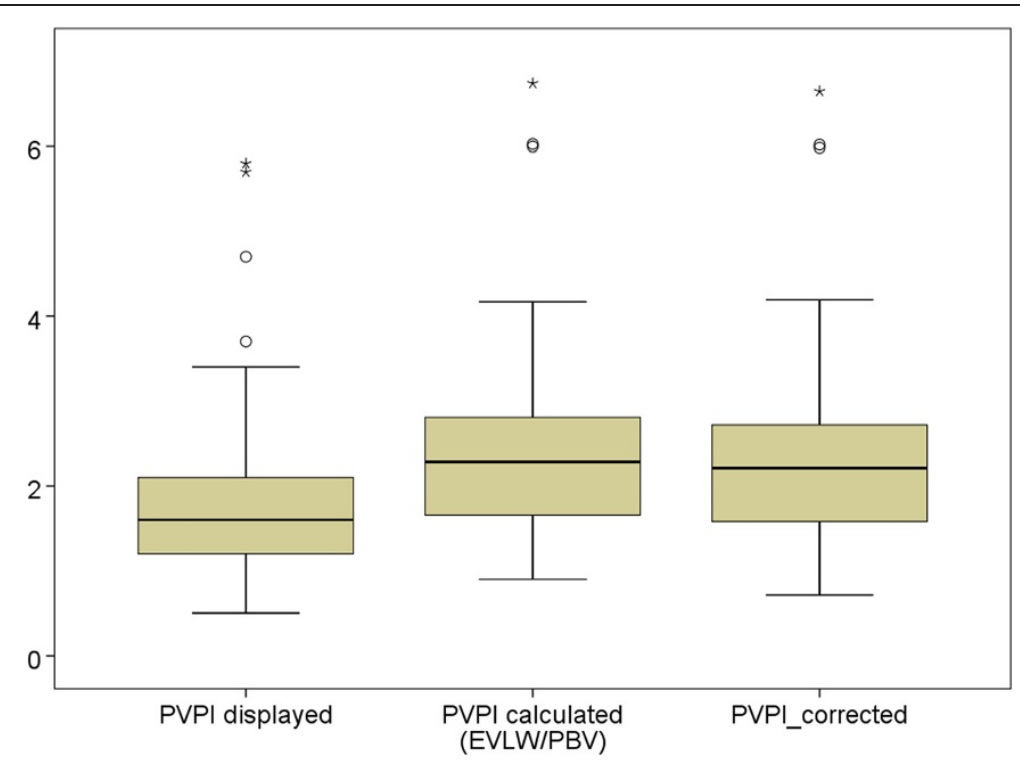

Figure 3 Boxplots plots comparing pulmonary vascular permeability index PVPI as displayed by the PiCCO-2 device (PVPI $\mathrm{displayed}$ ) vs. PVPI calculated as ratio of EVLW/PBV (extravascular lung water/pulmonary blood volume) vs. PVPI corrected using the formula suggested for correction of femoral indicator injection derived GEDV [16]: GEDVI corrected $\left[\mathrm{mL} / \mathrm{m}^{2}\right]=0.539 * \mathrm{GEDVI}_{\mathrm{uncorrected}}-15.17+$ 24.49* $\mathrm{Cl}_{\text {uncorrected }} 2.311 * \mathrm{BW}_{\text {ideal. }}$. Assuming that PVPI displayed was calculated based on GEDV and PBV not corrected for femoral injection,

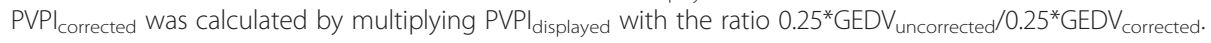

overload-particularly of the lungs-is another obvious approach to improve outcome in ARDS. EVLW has been validated as a significant predictor of outcome in ARDS [3,7-11]. However, with regard to fluid management it is important, if increased EVLW derives from inflammatory capillary leakage of the lungs or from general fluid overload and congestive heart failure. Relating EVLW to pulmonary blood volume, PVPI has been demonstrated to discriminate inflammatory from congestive pulmonary failure [13,14]. Therefore, combined use of EVLW and PVPI has been suggested to specify therapy in acute pulmonary failure. However, there are a number of studies suggesting pitfalls in using these parameters derived from TPTD: Due to its current indexation solely to bodyweight EVLWI might be inappropriately lowered in obese patients. Therefore, weight correction formulas [19] and

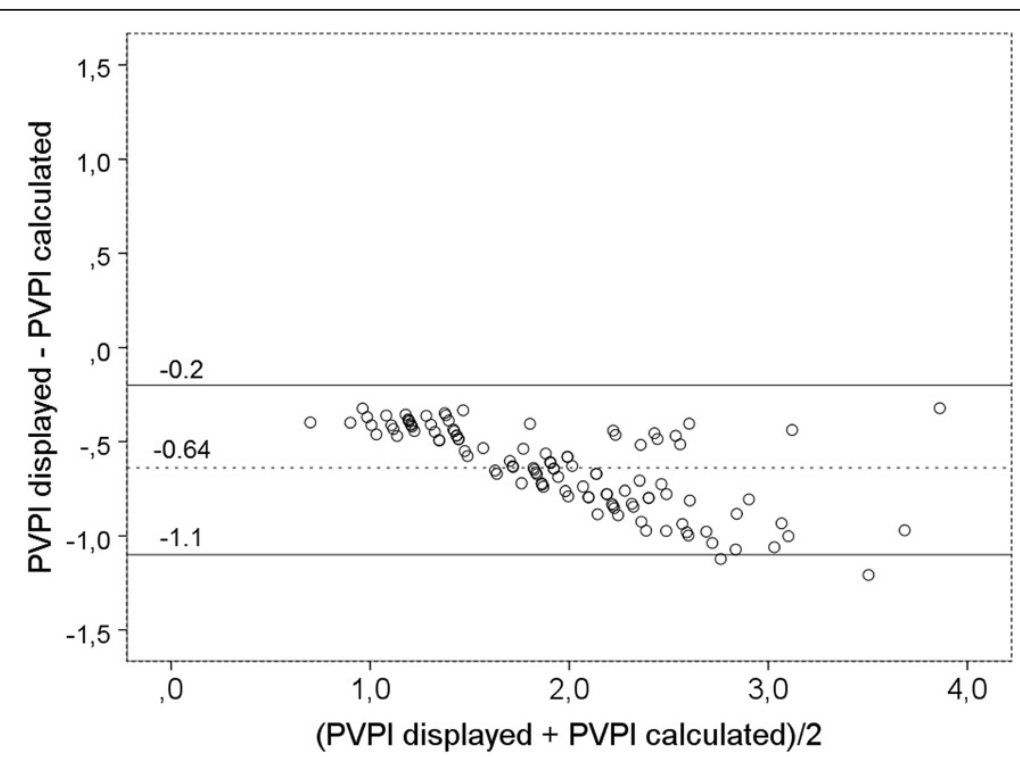

Figure 4 Bland Altman plot comparing pulmonary vascular permeability index PVPI as displayed by the PiCCO-2 device (PVPI displayed vs. PVPI calculated as ratio of EVLW/PBV (extravascular lung water/pulmonary blood volume). 


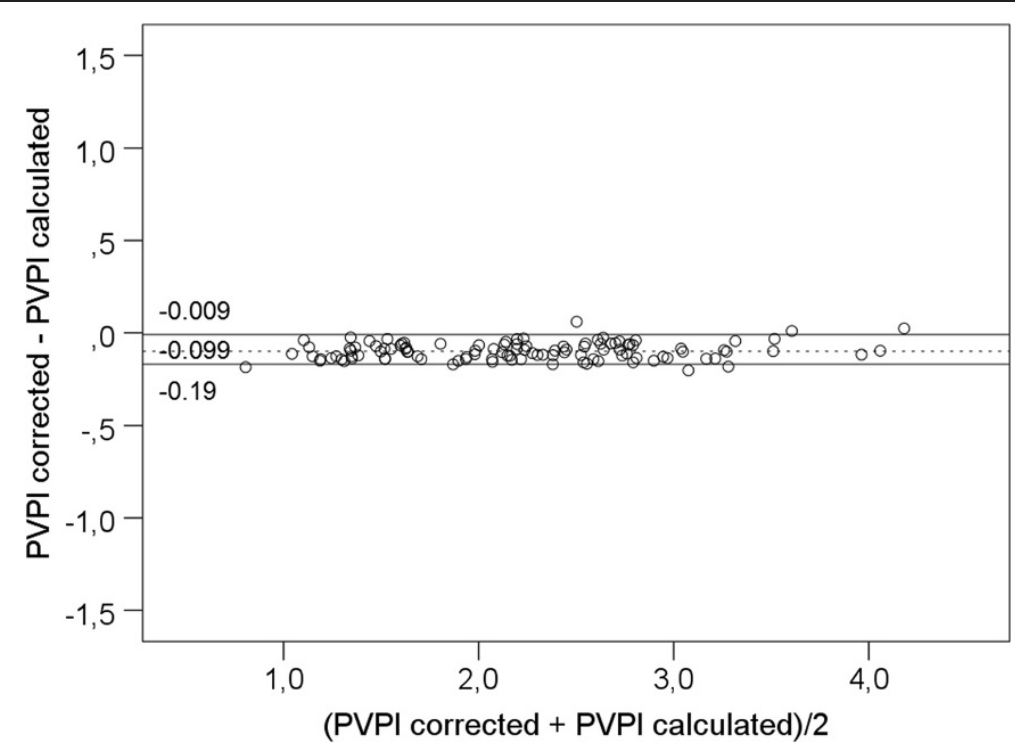

Figure 5 Bland Altman plot comparing pulmonary vascular permeability index PVPI $_{\text {displayed }}$ corrected by the correction formula for

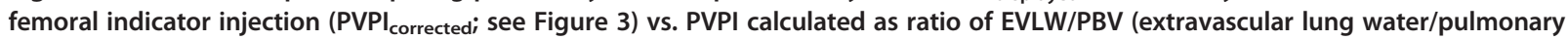
blood volume).

indexation of EVLWI to height [19,28] have been shown to improve usefulness of EVLWI. Furthermore, femoral central vein access for TPTD indicator injection inappropriately increases GEDV(I) $[15,16]$. Therefore, a correction formula for GEDVI in case of femoral CVC has been suggested [16]. Requirement of information about the CVC site in the last $\mathrm{PiCCO}$ algorithm suggests that some kind of correction for femoral CVC is provided. Due to the assumption that PBV is $25 \%$ of GEDV in single indicator TPTD $[6,12]$, overestimation of GEDV in femoral indicator TPTD indicator injection also pertains to PVPI.

However, no information is available,

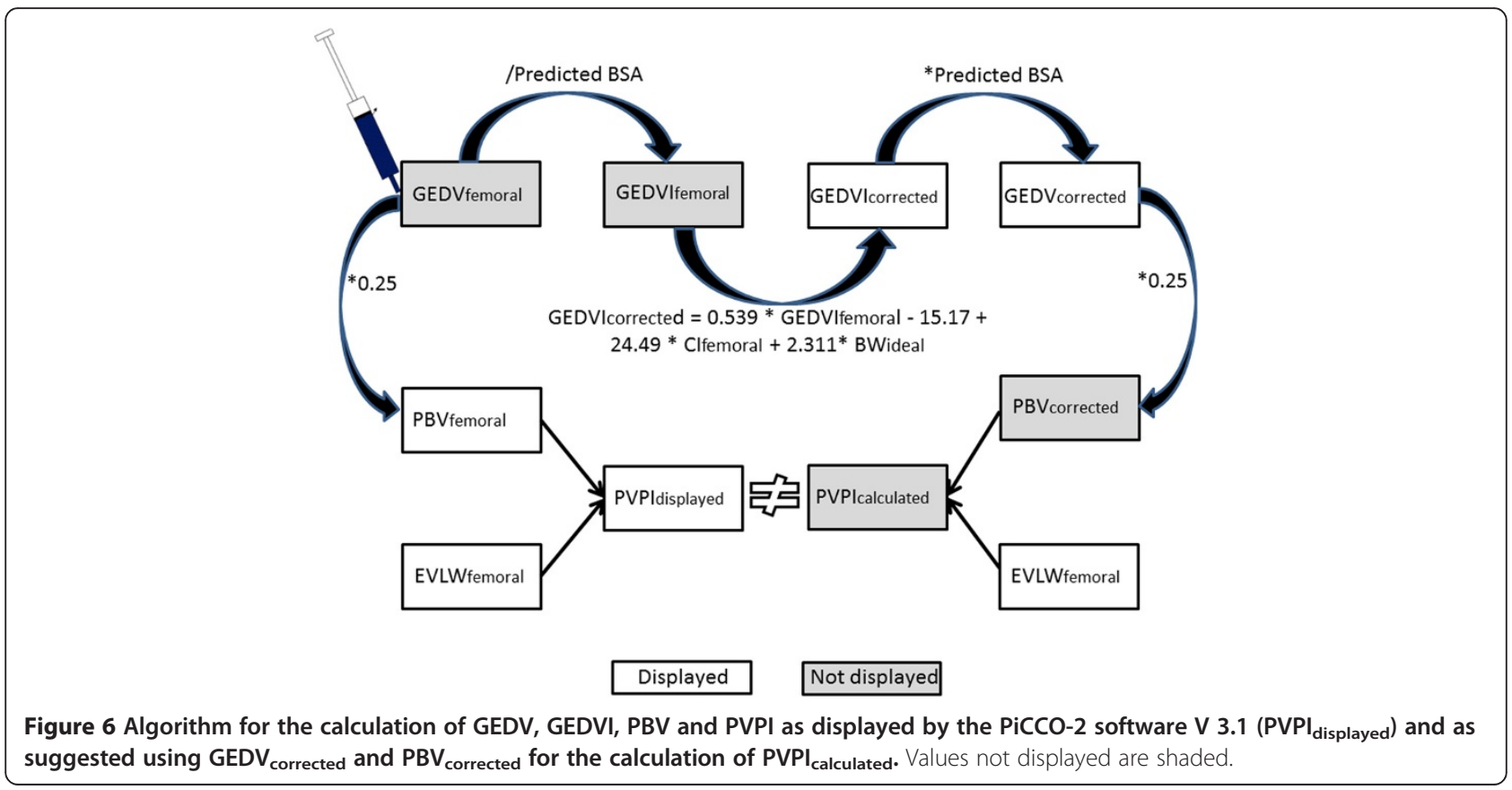


- if correction provided by the new PiCCO-algorithm applies only to GEDVI or also to GEDV

- if this correction is similar to the formula suggested by Saugel et al. [16] and

- if PVPI displayed $_{\text {is based on PBV and GEDV derived }}$ from the correction formula suggested by our group.

Therefore, we performed a prospective study in patients with femoral CVC access showing the following main results that are graphically summarized in Figure 6.

$\mathrm{GEDV}_{\text {displayed }}$ is corrected to the same degree as GEDVI $_{\text {displayed }}$.

However, PVPI ${ }_{\text {displayed }}$ provided by the PiCCO-device

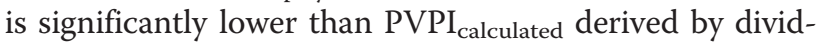
ing $E V L W$ displayed by $0.25 * G E D V_{\text {displayed }}$. This suggests the use of uncorrected GEDV and uncorrected PBV for the PVPI displayed by the device.

This assumption is supported by $\mathrm{PVPI}_{\text {corrected }}$ values nearly identical to $\mathrm{PVPI}_{\text {calculated }}$ when correcting PVPI $_{\text {displayed }}$ using the correction formula.

\section{Practical implications}

Our data strongly suggest that the correction formula for GEDVI in case of femoral CVC indicator injection should be also applied for the calculation of PVPI. Otherwise, PVPI would remain to be artificially lowered in case of femoral CVC which also would result in different PVPI threshold for inflammatory vs. congestive pulmonary impairment.

\section{Limitations of the study}

Despite conclusive results with high statistical significance this is a single centre study with a limited number of patients and TPTD measurements. Furthermore, we have to admit that our explanations for this inconsistency are in part speculative: Although correction of $\mathrm{PVPI}_{\text {displayed }}$ by our formula results in PVPI $\mathrm{Porrected}_{\text {close to }} \mathrm{PVPI}_{\text {displayed, }}$ the hypothesis of a "neglect" of correction of PBV has to be proven by a confirmatory study. Future studies should verify the practical implications, e.g. showing improved association of PVPI with outcome when applying the correction formula also for PBV and PVPI. Furthermore, our findings could be confirmed by comparing PVPI derived from femoral and jugular indicator injection in patients with both femoral and jugular CVC.

Finally, these findings pertain to the PiCCO-2 device with the V3.1 algorithm. To the best of our knowledge, there is only one other device providing PVPI which is the Edwards EV 1000 VolumeView (Edwards Lifesciences; Irvine, CA, USA). Despite some minor modifications of the thermodilution analysis this device is comparable to the PiCCO. However, the EV-1000 does not require information about the CVC site. This suggests that the device does neither correct GEDV(I) nor PVPI in case of femoral CVC site.

\section{Conclusion}

This study suggests that the V3.1 software of the PiCCOdevice corrects GEDVI and GEDV for TPTD indicator injection based on a correction formula similar to the correction recently suggested [16]. However, correction of GEDV(I) does not pertain to PVPI which is contradictory to the definition of PVPI and results in a substantial underestimation of PVPI. To make PVPI values derived from jugular and femoral indicator injection comparable, corrected GEDV and PBV should be used for calculation of PVPI in case of femoral CVC.

\section{Abbreviations}

APACHE-II: Acute physiology and chronic health evaluation-II; ARDS: Acute respiratory distress syndrome; BSA: Body surface area; CO: Cardiac output; Cl: Cardiac index; CVC: Central venous catheter; EVLW: Extravascular lung water; EVLWI: Extravascular lung water index; GEDV: Global end-diastolic volume; GEDVI: Global end-diastolic volume index; ICU: Intensive care unit; ITTV: Intrathoracic thermovolume; PBV: Pulmonary blood volume; PE: Percentage error; PTV: Pulmonary thermovolume; PVPI: Pulmonary vascular permeability index; RRT: Renal replacement-therapy; ROC: Receiver operating characteristics; SOFA: Sequential organ failure assessment score; TPTD: Transpulmonary thermodilution.

\section{Competing interests}

Wolfgang Huber collaborates with Pulsion Medical Systems Feldkirchen, Germany as member of the Medical Advisory Board. The other authors declare that they have no competing interest.

\section{Authors' contributions}

$\mathrm{HB}$ performed the majority of measurements, participated in analysis of the data and in drafting the manuscript and finally approved the manuscript. SM performed parts of the measurement, participated in analysis of the data and in drafting the manuscript and finally approved the manuscript. $A B$

performed parts of the measurement, participated in analysis of the data and in drafting the manuscript and finally approved the manuscript. BH performed parts of the measurement, participated in analysis of the data and in drafting the manuscript and finally approved the manuscript. RS substantially contributed to conception and design of the study, participated in the analysis of the data, participated in drafting the manuscript and finally approved the manuscript. WH performed conception and design of the study, analyzed the data, drafted the manuscript and finally approved the manuscript.

\section{Acknowledgements}

Funding: Helena Berbara is funded by the CAPES Foundation, Ministry of Education of Brazil, Brasilia DF, Zip Code 70.040-020.

There are no other sources of funding.

There are no further acknowledgements to be made.

Received: 13 April 2014 Accepted: 11 September 2014

Published: 24 September 2014

\section{References}

1. Michard F, Alaya S, Zarka V, Bahloul M, Richard C, Teboul JL: Global enddiastolic volume as an indicator of cardiac preload in patients with septic shock. Chest 2003, 124:1900-1908.

2. Reuter DA, Huang C, Edrich T, Shernan SK, Eltzschig HK: Cardiac output monitoring using indicator-dilution techniques: basics, limits, and perspectives. Anesth Analg 2010, 110:799-811.

3. Sakka SG, Klein M, Reinhart K, Meier-Hellmann A: Prognostic value of extravascular lung water in critically ill patients. Chest 2002, 122:2080-2086. 
4. Tagami T, Kushimoto S, Yamamoto Y, Atsumi T, Tosa R, Matsuda K, Oyama R, Kawaguchi T, Masuno T, Hirama H, Yokota H: Validation of extravascular lung water measurement by single transpulmonary thermodilution: Human autopsy study. Crit Care 2010, 14:R162.

5. Kuzkov W, Kirov MY, Sovershaev MA, Kuklin VN, Suborov EV, Waerhaug K, Bjertnaes LJ: Extravascular lung water determined with single transpulmonary thermodilution correlates with the severity of sepsisinduced acute lung injury. Crit Care Med 2006, 34:1647-1653.

6. Huber W, Umgelter A, Reindl W, Franzen M, Schmidt C, Von Delius S, Geisler F, Eckel F, Fritsch R, Siveke J, Henschel B, Schmid RM: Volume assessment in patients with necrotizing pancreatitis: a comparison of intrathoracic blood volume index, central venous pressure, and hematocrit, and their correlation to cardiac index and extravascular lung water index. Crit Care Med 2008, 36:2348-2354.

7. Phillips CR, Chesnutt MS, Smith SM: Extravascular lung water in sepsisassociated acute respiratory distress syndrome: Indexing with predicted body weight improves correlation with severity of illness and survival. Crit Care Med 2008, 36:69-73.

8. Craig TR, Duffy MJ, Shyamsundar M, McDowell C, McLaughlin B, Elborn JS, McAuley DF: Extravascular lung water indexed to predicted body weight is a novel predictor of intensive care unit mortality in patients with acute lung injury. Crit Care Med 2010, 38:114-120.

9. Chew MS, Ihrman L, During J, Bergenzaun L, Ersson A, Unden J, Ryden J, Akerman E, Larsson M: Extravascular lung water index improves the diagnostic accuracy of lung injury in patients with shock. Crit Care 2012, 16:R1.

10. Mallat J, Pepy F, Lemyze M, Barrailler S, Gasan G, Tronchon L, Thevenin D: Extravascular lung water indexed or not to predicted body weight is a predictor of mortality in septic shock patients. J Crit Care 2012, 27:376-383.

11. Jozwiak M, Silva S, Persichini R, Anguel N, Osman D, Richard C, Teboul JL, Monnet $X$ : Extravascular lung water is an independent prognostic factor in patients with acute respiratory distress syndrome. Crit Care Med 2013, 41:472-480

12. Goepfert MS, Reuter DA, Akyol D, Lamm P, Kilger E, Goetz AE: Goal-directed fluid management reduces vasopressor and catecholamine use in cardiac surgery patients. Intensive Care Med 2007, 33:96-103.

13. Groeneveld $A B$, Verheij J: Extravascular lung water to blood volume ratios as measures of permeability in sepsis-induced ali/ards. Intensive Care Med 2006, 32:1315-1321.

14. Monnet X, Anguel N, Osman D, Hamzaoui O, Richard C, Teboul JL: Assessing pulmonary permeability by transpulmonary thermodilution allows differentiation of hydrostatic pulmonary edema from ali/ards. Intensive Care Med 2007, 33:448-453.

15. Schmidt S, Westhoff TH, Hofmann C, Schaefer JH, Zidek W, Compton F, Van der Giet M: Effect of the venous catheter site on transpulmonary thermodilution measurement variables. Crit Care Med 2007, 35:783-786.

16. Saugel B, Umgelter A, Schuster T, Phillip V, Schmid RM, Huber W: Transpulmonary thermodilution using femoral indicator injection: a prospective trial in patients with a femoral and a jugular central venous catheter. Crit Care 2010, 14:R95.

17. Gowardman JR, Robertson IK, Parkes S, Rickard CM: Influence of insertion site on central venous catheter colonization and bloodstream infection rates. Intensive Care Med 2008, 34:1038-1045.

18. Deshpande KS, Hatem C, Ulrich HL, Currie BP, Aldrich TK, Bryan-Brown CW, Kvetan $\mathrm{V}$ : The incidence of infectious complications of central venous catheters at the subclavian, internal jugular, and femoral sites in an intensive care unit population. Crit Care Med 2005, 33:13-20. discussion 234-235.

19. Huber W, Mair S, Gotz SQ, Tschirdewahn J, Siegel J, Schmid RM, Saugel B: Extravascular lung water and its association with weight, height, age, and gender: a study in intensive care unit patients. Intensive Care Med 2013, 39:146-150.

20. Bland JM, Altman DG: Statistical methods for assessing agreement between two methods of clinical measurement. Lancet 1986, 1:307-310.

21. Critchley LA, Critchley JA: A meta-analysis of studies using bias and precision statistics to compare cardiac output measurement techniques. J Clin Monit Comput 1999, 15:85-91.

22. Bland JM, Altman DG: Agreement between methods of measurement with multiple observations per individual. J Biopharm Stat 2007 17:571-582.
23. Ventilation with lower tidal volumes as compared with traditional tidal volumes for acute lung injury and the acute respiratory distress syndrome: the acute respiratory distress syndrome network. N Engl J Med 2000, 342:1301-1308.

24. Peek GJ, Mugford M, Tiruvoipati R, Wilson A, Allen E, Thalanany MM, Hibbert CL, Truesdale A, Clemens F, Cooper N, Firmin RK, Elbourne D: Efficacy and economic assessment of conventional ventilatory support versus extracorporeal membrane oxygenation for severe adult respiratory failure (cesar): a multicentre randomised controlled trial. Lancet 2009, 374:1351-1363.

25. Guerin C, Reignier J, Richard JC, Beuret P, Gacouin A, Boulain T, Mercier E, Badet M, Mercat A, Baudin O, Clavel M, Chatellier D, Jaber S, Rosselli S, Mancebo J, Sirodot M, Hilbert G, Bengler C, Richecoeur J, Gainnier M, Bayle F, Bourdin G, Leray V, Girard R, Baboi L, Ayzac L: Prone positioning in severe acute respiratory distress syndrome. N Engl J Med 2013, 368:2159-2168.

26. Putensen $\mathrm{C}$, Theuerkauf $\mathrm{N}$, Zinserling J, Wrigge $\mathrm{H}$, Pelosi P: Meta-analysis: ventilation strategies and outcomes of the acute respiratory distress syndrome and acute lung injury. Ann Intern Med 2009, 151:566-576.

27. Rivers E, Nguyen B, Havstad S, Ressler J, Muzzin A, Knoblich B, Peterson E, Tomlanovich M: Early goal-directed therapy in the treatment of severe sepsis and septic shock. N Engl J Med 2001, 345:1368-1377.

28. Wolf S, Riess A, Landscheidt JF, Lumenta CB, Schurer L, Friederich P: How to perform indexing of extravascular lung water: a validation study. Crit Care Med 2013, 41:990-998.

doi:10.1186/1471-2253-14-81

Cite this article as: Berbara et al:: Pulmonary vascular permeability index and global end-diastolic volume: are the data consistent in patients with femoral venous access for transpulmonary thermodilution: a prospective observational study. BMC Anesthesiology 2014 14:81.

\section{Submit your next manuscript to BioMed Central and take full advantage of:}

- Convenient online submission

- Thorough peer review

- No space constraints or color figure charges

- Immediate publication on acceptance

- Inclusion in PubMed, CAS, Scopus and Google Scholar

- Research which is freely available for redistribution 